\title{
Low-Dimensional Pseudoboehmite Structures for Microorganism Adsorption
}

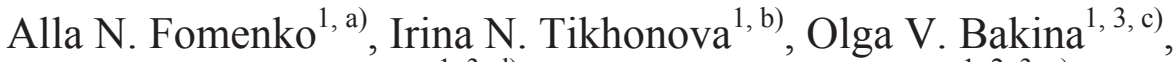 \\ Elena A. Glazkova ${ }^{1,3, \text { d) }}$, Natalia V. Svarovskaya ${ }^{1,2,3, \text { e) }}$ \\ Aleksandr S. Lozhkomoev ${ }^{1,3, \text { f) }}$, and Sergey G. Psakhie ${ }^{1,3, g}$ ) \\ ${ }^{1}$ Institute of Strength Physics and Materials Science SB RAS, Tomsk, 634055, Russia \\ ${ }^{2}$ National Research Tomsk State University, Tomsk, 634050, Russia \\ ${ }^{3}$ National Research Tomsk Polytechnic University, Tomsk, 634050, Russia \\ a) Corresponding author: alserova@ispms.tsc.ru \\ b) inti@ispms.tsc.ru \\ c) ovbakina@ispms.tsc.ru \\ d)eagl@ispms.tsc.ru \\ e)nvsv@ispms.tsc.ru \\ f) asl@ispms.tsc.ru \\ g) sp@ms.tsc.ru
}

\begin{abstract}
Low-dimensional structures consisting of pseudoboehmite nanopetals are synthesized by hydrolysis of electroexplosive aluminum nanopowder. The physical and chemical properties of the synthesized nanostructures are studied, such as morphology, particle size, specific surface area, phase composition, and zeta-potential. The production of a hybrid material on the basis of cellulose acetate microfibers and low-dimensional pseudoboehmite structures is described. Using the example of gram-negative and gram-positive bacteria, we show the microorganism adsorption capacity of pseudoboehmite nanopetals and the hybrid material.
\end{abstract}

Keywords: electroexplosive nanopowder, hydrolysis, low-dimensional structures, pseudoboehmite, hybrid material, bacteria adsorption

\section{INTRODUCTION}

Bacteria adsorption on mineral and synthetic surfaces, including electrostatic, covalent and polymer-polymer interactions, is undergoing extensive studies $[1,2]$. Researchers show that the high bacteria adsorption capacity is mostly determined by electrostatic interaction $[3,4]$. The bacterial cell surface contains different functional groups, such as carboxylates, phosphates, hydroxyls and other, which are deprotonated depending on the $\mathrm{pH}$ of the medium and thus the cell acquires a negative electrostatic charge at physiological $\mathrm{pH}$ values [5]. In this respect, adsorbents with positively charged surface are the most efficient for microorganism adsorption $[6,7]$. A reduction of adsorbent particle size down to $2 \mu \mathrm{m}$ and less increases several times the bacteria adsorption capacity [8], which makes lowdimensional structures particularly interesting. Low-dimensional aluminum oxides and hydroxides are being extensively studied as they demonstrate good adsorption capacities for bioobjects. Of particular interest are particles consisting of pseudoboehmite nanosheets or nanopetals [9] arranged into three-dimensional multi-level porous structures. Owing to a large specific surface area and open porosity, they have high adsorption capacity for bacteria, viruses, DNA/RNA, proteins, endotoxins, and antigens [10]. Such particles can be used for the development of wound-healing products whose performance is based on wound exudate absorption, on adsorption and inactivation of pathogens. Besides, porous agglomerates of nanopetal pseudoboehmite are easily attached to natural or synthetic

(C) 2014 AIP Publishing LLC 978-0-7354-1260-6/\$30.00 
polymer fibers. This allows one to combine useful properties of polymer matrix (mechanical strength, chemical resistance, low fluid resistance) and unique adsorption properties of low-dimensional structures [11]. By attaching single nanopetals and their agglomerates to microfibers, it is possible to produce a fibrous material with positively charged effective surface easily accessible for microorganisms.

The aim of this paper is to study the physical and chemical characteristics of low-dimensional structures of pseudoboehmite, its adsorption properties, and antimicrobial activity of a hybrid material on its basis.

\section{EXPERIMENTAL PROCEDURE}

Aluminum nanopowder (precursor) for the investigation was obtained by electric explosion of aluminum conductor in argon atmosphere (LLC Advanced Powder Technology, Tomsk, Russia, TU 1791-003-362803402008). Microfibers were made of cellulose acetate by electroforming, grade FPA-15-2.0 (Esfil Tehno, Estonia); the average fiber diameter is $1.5 \mu \mathrm{m}$, the density is $1.28 \mathrm{~g} / \mathrm{cm}^{3}$.

The morphology of samples was examined by transmission electron microscopy (JEM 2100, JEOL, Japan) and scanning electron microscopy (LEO EVO 50, Zeiss, Germany). The zeta potential of low-dimensional structures was determined by electrophoretic light scattering in distilled water (Zetasizer Nano ZS, Malvern Instruments, UK). The phase composition was determined by $\mathrm{X}$-ray diffraction with $\mathrm{CuK}_{\alpha}$ radiation, $\lambda=1.54056 \AA$ (diffractometer XRD-6000, Shimadzu). Texture characteristics were evaluated by thermal desorption of nitrogen (Sorbometr M, Katakon, Russia), and the specific surface area was evaluated by the five-point BET method.

Low-dimensional structures were produced as follows: $0.5 \mathrm{~g}$ of aluminum nanopowder were added to $50 \mathrm{ml}$ of distilled water $(1 \mathrm{mass} \%)$. The suspension was heated up to $60^{\circ} \mathrm{C}$ for $60 \mathrm{~min}$ until aluminum nanopowder oxidation was completed. The obtained low-dimensional structures of aluminum oxide were filtered, rinsed in distilled water and dried at $105^{\circ} \mathrm{C}$ for 4 hours.

In order to obtain a hybrid material, $0.5 \mathrm{~g}$ of cellulose acetate microfibers were added to $50 \mathrm{ml}$ of the aluminum nanopowder suspension ( 1 mass $\%$ ) in distilled water and heated up to $60^{\circ} \mathrm{C}$ for $60 \mathrm{~min}$ until the reaction stops. The sample of cellulose acetate microfibers with agglomerates of low-dimensional pseudoboehmite structures attached to their surface was pulled from the reaction vessel, rinsed in distilled water and dried at $105^{\circ} \mathrm{C}$ for 4 hours.

The microorganism adsorption capacity and antimicrobial activity of the hybrid material was studied under static conditions. Studies were carried out using Escherichia coli 7935 as gram-positive and Staphylococcus aureus 209 as gram-negative bacteria. The microorganism adsorption was studied in the following way: $0.1 \mathrm{~g}$ of the hybrid material was added to $50 \mathrm{ml}$ of a $10^{7} \mathrm{CFU} / \mathrm{ml}$ aqueous suspension of bacteria. The obtained mixture was incubated at room temperature at constant shaking. Then, the hybrid material was separated by centrifuging and the number of microorganisms in the supernate was counted. The antimicrobial activity of the hybrid material was studied by agar diffusion in the Kirby-Bauer modification [12]. The hybrid material samples of diameter $47 \mathrm{~mm}$ were placed into Petri dishes on a bacterial lawn with concentration $10^{7} \mathrm{CFU} / \mathrm{ml}$ and incubated in a thermostat at temperature $(37 \pm 1)^{\circ} \mathrm{C}$. After 24 hours of incubation the samples were removed from the lawn, and bacteria that had grown under the samples were swabbed and inoculated into beef-extract agar.

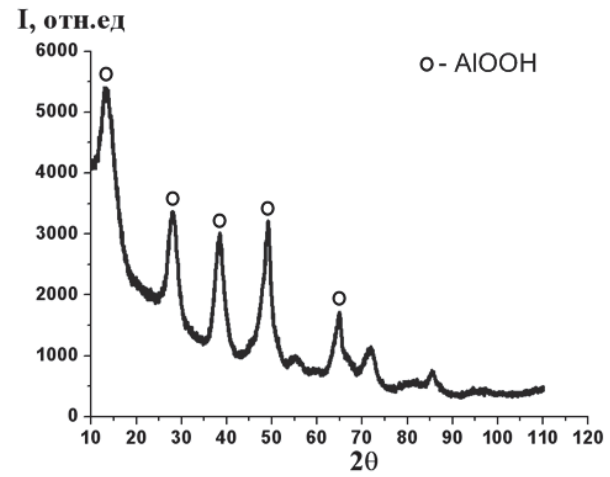

FIGURE 1. Diffraction pattern of low-dimensional pseudoboehmite structures

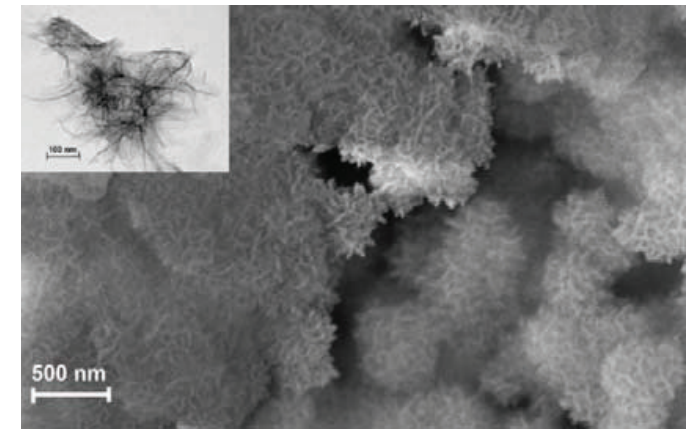

FIGURE 2. Electron microscopic image of pseudoboehmite nanopetals 

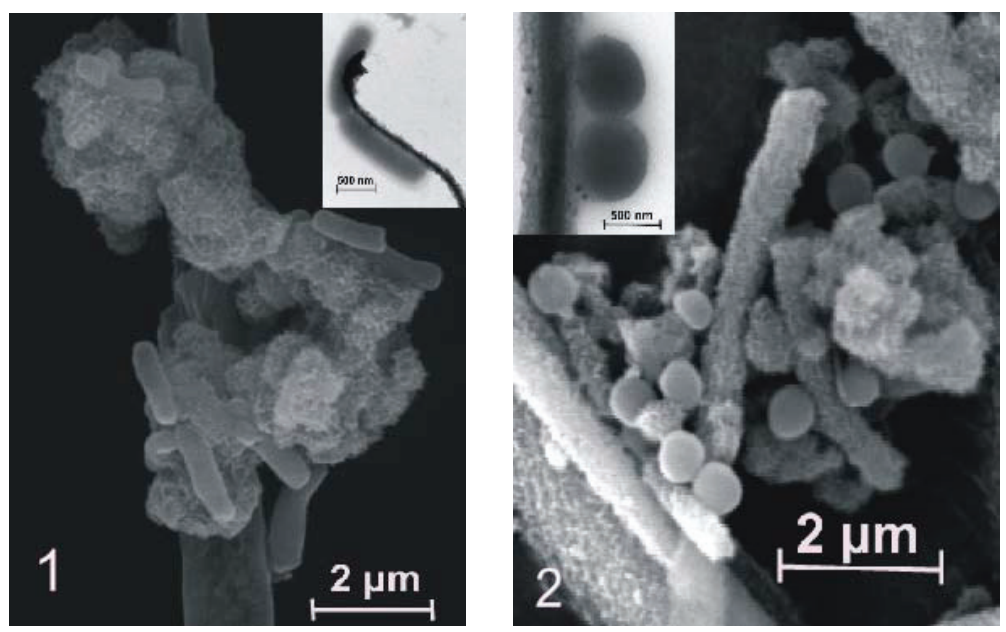

FIGURE 3. Electron microscopic images of E. coli (1) and St. Aureus bacteria (2) on the hybrid material surface

\section{DISCUSSION OF RESULTS}

A precursor for the production of low-dimensional aluminum oxide structures is aluminum nanoparticles synthesized by electric explosion of aluminum conductor in argon atmosphere. The nanoparticles are covered by an oxide film of thickness $10-15 \AA$ as a result of passivation in air. The number-average size of aluminum nanoparticles is $100 \mathrm{~nm}$; they are compacted into agglomerates of size $0.5-1.5 \mu \mathrm{m}$. Due to their high chemical activity, aluminum nanoparticles react with water at room temperature in the range of $\mathrm{pH}=6-9$. The reaction is accompanied by $\mathrm{pH}$ growth of the reaction medium and by a release of a large quantity of heat. Interaction of water with aluminum nanopowder results in the formation of three-dimensional porous agglomerates made of lowdimensional aluminum oxide structures in the form of nanopetals (Figs. 1,2).

X-ray diffraction analysis has shown that low-dimensional structures consist of poorly crystallized pseudoboehmite (Fig. 1). It is found by TEM method that particles have the shape of curved petals of thickness less than $8 \mathrm{~nm}$ and size 100-200 nm compacted into three-dimensional porous agglomerates of size 0.5-5.0 $\mu \mathrm{m}$ (Fig. 2). The specific surface area of pseudoboehmite nanopetals agglomerates reaches $380 \mathrm{~m}^{2} / \mathrm{g}$. The adsorption-desorption isotherm has a hysteresis loop in the domain of capillary condensation at pressure ratio $>0.4$ which is typical for slitlike pores of size 4-10 nm. The zeta potential of particles is about $40 \mathrm{mV}$. The hybrid material consists of polymer microfibers with attached porous agglomerates of low-dimensional structures. The mass fraction of pseudoboehmite on the microfiber surface is about $30 \%$. The specific surface area of the adsorbent material is $150 \mathrm{~m}^{2} / \mathrm{g}$.
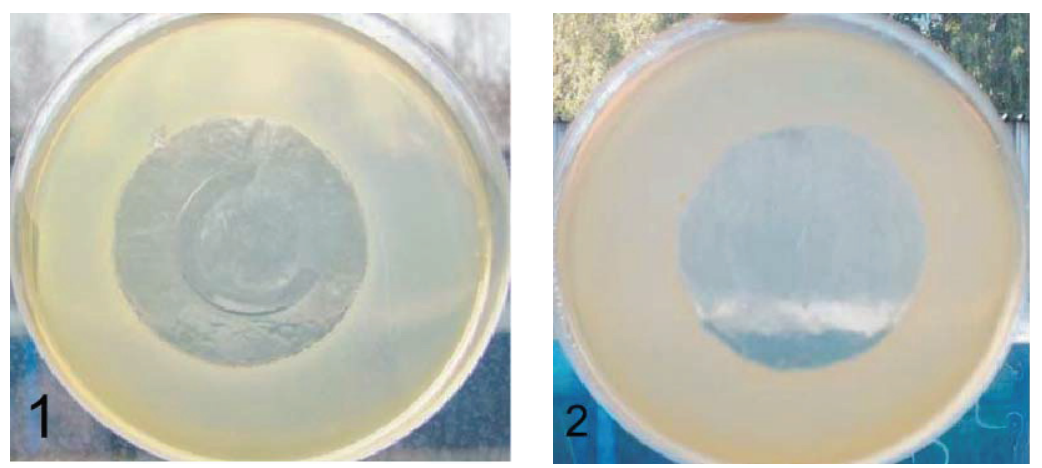

FIGURE 4. Concentration of E. coli (1) and St. aureus bacteria (2) under the adsorbent material 
It was shown in studying the microorganism adsorption capacity of the hybrid material with low-dimensional structures that the time of complete microorganism adsorption under static conditions is 24 hours for E. coli and 72 hours for St. aureus (Fig. 3).

The E. Coli and St. aureus concentration under the hybrid material samples reduced by 3 orders of magnitude during 24 hours for both types of bacteria (Fig. 4).

\section{CONCLUSION}

The paper describes the production of electropositive porous low-dimensional pseudoboehmite structures synthesized in interaction between water and electroexplosive aluminum nanopowder as well as the production of a hybrid material on the basis of porous agglomerates of low-dimensional structures. The produced materials exhibit high adsorption capacity and antimicrobial activity with respect to microorganisms of different morphology. Therefore, the materials can be used in the manufacture of wound dressings for wound healing.

\section{ACKNOWLEDGEMENTS}

The present work was financially supported by Program of Fundamental Researches of the State Academies of Sciences for 2013-2020.

The authors are grateful to K. B. Krukovsky and A. A. Miller, and to researchers of the Nanotech Sharing Center of ISPMS SB RAS for electron microscopic investigations.

\section{REFERENCES}

1. S. Qiu, F. Ma, X. Huang, and S. Xu, Water Sci. Tech. 69, 407 (2014).

2. Y. Cao, X. Wei, P. Cai, Q. Huang, X. Rong, and W. Liang, Coll. Surf. B 83, 122 (2011).

3. W. Zhao, X. Liu, Q. Huang, S. Walker, and P. Cai, App. Clay Sci. 69, 37 (2012).

4. D. H. Jiang, Q. Y. Huang, P. Cai, X. M. Rong, and W. L. Chen, Coll. Surf. B 54, 217 (2007).

5. I. Bundeleva, L. S. Shirokova, P. Bénézeth, O. S. Pokrovsky, E. I. Kompantseva, and S. Balor, J. Coll. Interface Sci. 360, 100 (2011).

6. O. Zemb, M. Manefield, F. Thomas, and S. Jacquet, J. Virological Meth. 189, 283 (2013).

7. Z. Liu, J. Jiang, Z. Hong, and R. Xu, Coll. Surf. B 110, 289 (2013).

8. D. M. Oliver, C. D. Clegg, A. L. Heathwaite, and P. M. Haygarth, Water, Air, Soil Pollut. 185, 369 (2007).

9. N. V. Svarovskaya, O. V. Bakina, E. A. Glazkova, M. I. Lerner, and S. G. Psakhie, Russ. J. Phys. Chem. A 84, 1566 (2010).

10. M. I. Lerner, O. V. Bakina, E. A. Glazkova, A. S. Lozhkomoev, N. V. Svarovskaya, and S. G. Psakhie, Inorg. Mat. 2, 488 (2011).

11. A. S. Lozhkomoev, E. A. Glazkova, E. G. Khorobraya, M. I. Lerner, A. N. Maltsev, and V. G. Podkovyrov, Russ. Phys. J. 56, 384 (2013).

12. A. W. Bauer, W. M. Kirby, J. C. Sherris, and M. Turck, Am. J. Clin. Pathol. 36, 493 (1966). 